\title{
Drug survival of anti tumor necrosis factor $\alpha$ in patients with spondyloarthritis : The Tunisian experience
}

\section{Essafi F, Saidane O, Mahmoud I, Ben Tekaya A, Tekaya R, Abdelmoula L Department of Rheumatology, Charles Nicolle hospital}

Objectives: The aim of this study was to evaluate and to compare drug retention between the 3 antiTNF marketed in Tunisia.

Methods: We achieved a retrospective descriptive and comparative monocentric study, on 26 patients, with spondyloarthritis (SpA) including psoriatic arthritis (psA), enteropathic arthritis (EA), reactive arthritis $(\operatorname{Re} A)$ and undifferentiated spondyloarthritis (USpA) (according to ASAS 2009 and CASPAR), during 12 years (2004-2015). The patients were treated with at least one anti-TNF, during at least 6 months. All patients with EA were treated by antiTNF monoclonal antibodies. Drug survival was analysed by means of Kaplan-Meier curves

\section{Results:}

\begin{tabular}{|l|l|}
\hline Patients & $\mathbf{2 6}$ \\
\hline Sexe ratio & 0,5 \\
\hline Mean age (years) & $45,7 \pm 10,77$ \\
\hline Mean disease duration (years) & $10,16 \pm 8,88$ \\
\hline $\begin{array}{l}\text { median duration of prescription of anti-TNF } \\
\text { therapy (years) }\end{array}$ & 3,24 \\
\hline
\end{tabular}

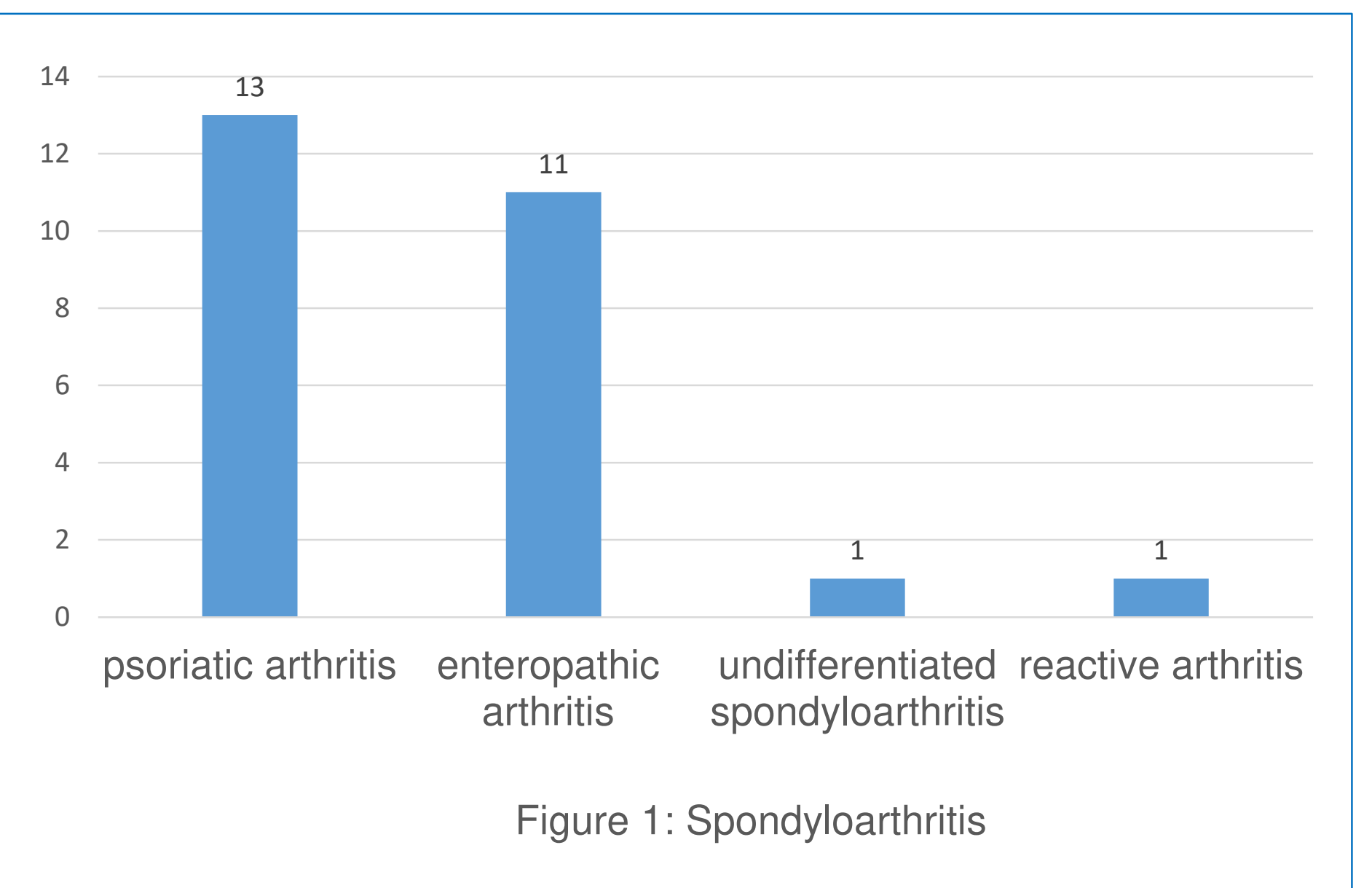

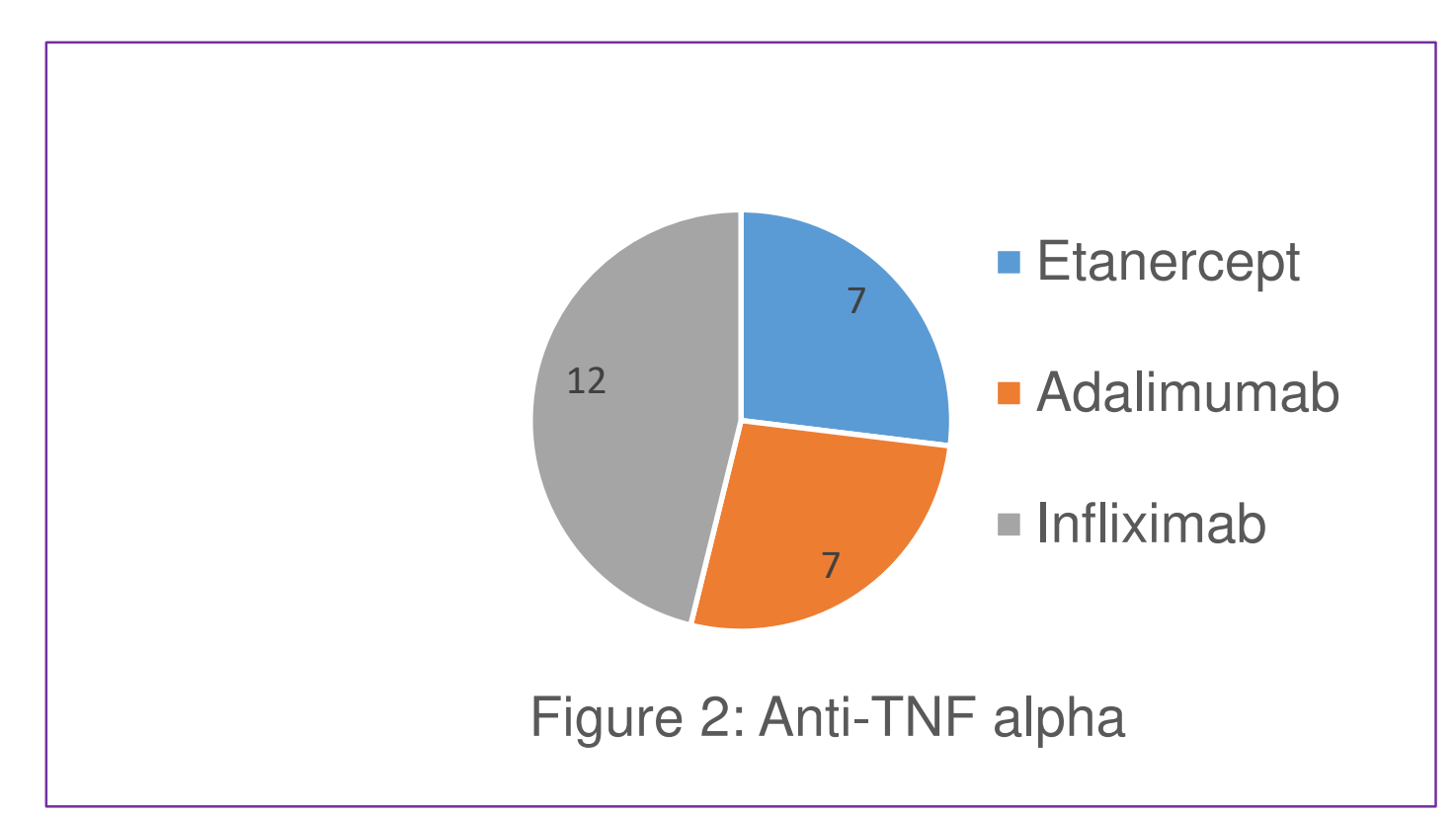

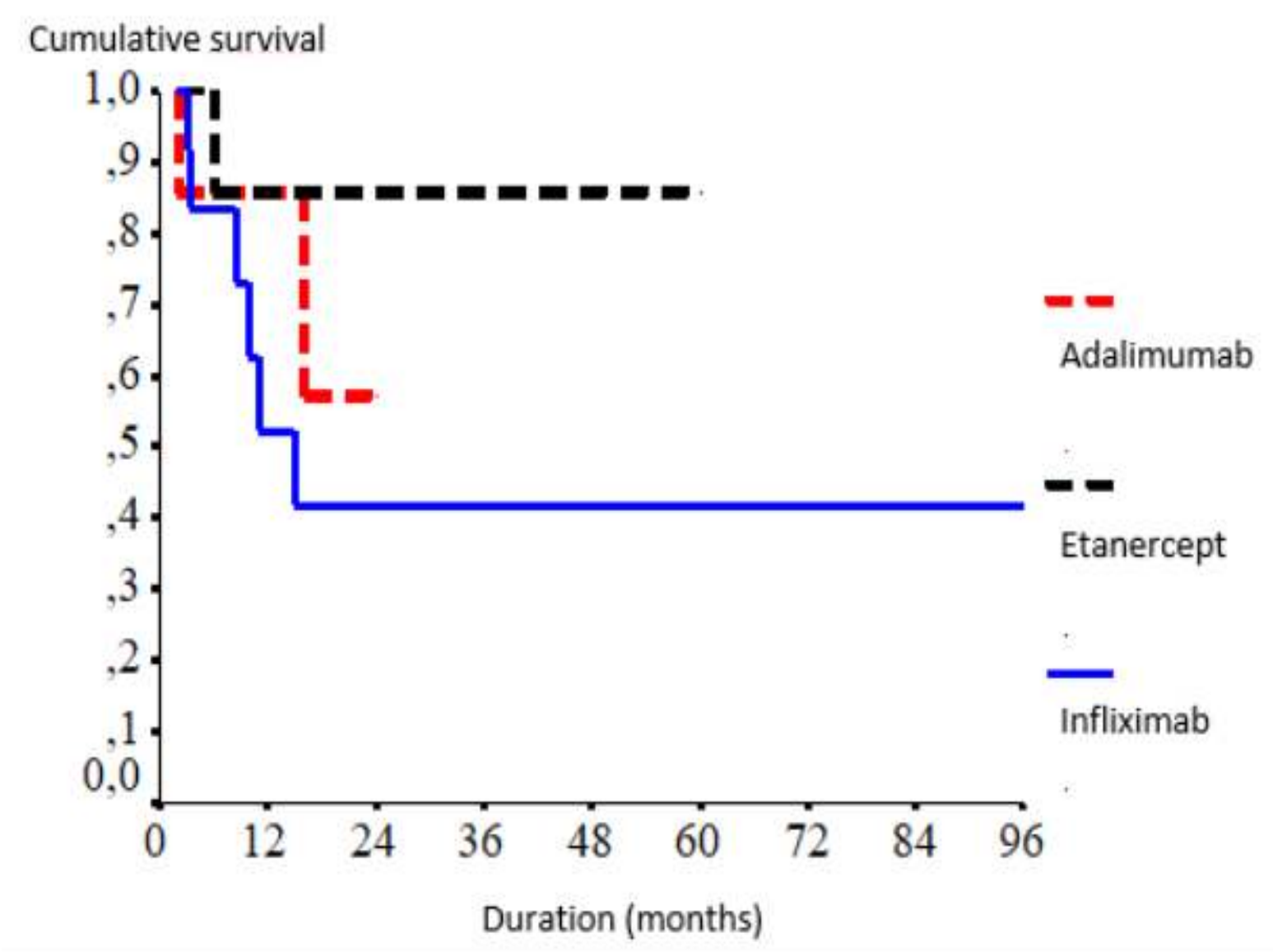

Figure 3: Eight-year drug survival rates by TNF inhibitor in spondyloarthritis

\begin{tabular}{|r|r|}
\hline Reasons for discontinuing & case \\
s \\
\hline lack of efficacy & 3 \\
\hline Adverse event & 4 \\
\hline Death & 1 \\
\hline
\end{tabular}

One case of death occurred in a patient with ReA treated with IFX. The death was due to gastrointestinal bleeding with indomethacin. This incident had no direct or indirect relationship with IFX.

Conclusion: This study demonstrated that anti-TNF showed a satisfactory and comparable drug survival in SpA treatment 